\title{
Yod
}

Revue des études hébraïques et juives

$14 \mid 2009$

La littérature israélienne, miroir d'une société multiple

\section{Littérature arabe en Israël : vers une sensibilité nouvelle}

Arabic Literature in Israel: Towards a New Sensibility

ספרות ערבית בישראל

\section{Sobhi Boustani}

\section{(2) OpenEdition}

Journals

Édition électronique

URL : https://journals.openedition.org/yod/342

DOI : $10.4000 /$ yod. 342

ISSN : 2261-0200

Éditeur

INALCO

Édition imprimée

Date de publication : 1 octobre 2009

Pagination : 93-104

ISBN : 978-2-85831-178-1

ISSN : 0338-9316

\section{Référence électronique}

Sobhi Boustani, «Littérature arabe en Israël : vers une sensibilité nouvelle », Yod [En ligne], 14 | 2009,

mis en ligne le 31 octobre 2011, consulté le 08 juillet 2021. URL : http://journals.openedition.org/yod/ 342 ; DOI : https://doi.org/10.4000/yod.342

Ce document a été généré automatiquement le 8 juillet 2021.

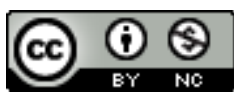

Yod est mis à disposition selon les termes de la Licence Creative Commons Attribution - Pas d'Utilisation Commerciale 4.0 International. 


\section{Littérature arabe en Israël : vers une sensibilité nouvelle}

Arabic Literature in Israel: Towards a New Sensibility

ספרות ערבית בישראל

Sobhi Boustani

1 Admettre comme une évidence le rapport qui s'installe entre l'œuvre littéraire et le contexte sociopolitique qui préside à sa genèse, c'est installer d'emblée la littérature arabe en Israël dans une problématique singulière. Régie par deux contextes plutôt conflictuels et discordants, l'un israélien immédiat et l'autre plus large, palestinoarabe, cette littérature est difficilement saisissable indépendamment de la conjoncture régionale. La littérature arabe en Israël - pour des raisons diverses - s'est imposée après la guerre de 1967 comme un élément essentiel dans les champs culturels et littéraires israélien et arabe. Un lien étroit et interdépendant s'est tissé entre la littérature palestinienne arabe dite de l'intérieur et la littérature arabe et palestinienne dite de l'extérieur. Je me limiterai, dans cet article, à l'écriture poétique arabe en Israël, et j'essaierai d'en dégager les mouvements marquant son évolution ainsi que ses valeurs esthétiques.

2 Ma communication sera en 3 parties : 1 - poésie à caractère militant; 2 - une nouvelle sensibilité fondée sur l'individualité et l'expérience personnelle; 3 - une nouvelle voix intimiste : une voix féminine.

\section{Poésie à caractère militant}

Baptisée «Littérature de la résistance " par Ghassan Kanafânî (1936-1972), un écrivain palestinien de «l'extérieur", la littérature palestinienne à l'intérieur d'Israël abandonne, surtout après 1967, la « lamentation » pour le « militantisme ». ${ }^{1}$

Les poètes de cette tendance, en rapport direct avec la gauche israélienne, sont souvent des adhérents ou des sympathisants du parti communiste Rakah et trouvent dans l'hebdomadaire al-Ittihâd (l'Union) et son supplément littéraire al-Jadîd (Le Nouveau) 
une tribune pour diffuser leur littérature. Trois poètes représentent particulièrement cette tendance : Tûfîq Zayyâd, Sâlim Jubrân et Shafîq Habîb.

Tûfîqc Zayyâd (1929-1994), membre du parti communiste israélien Rakah et député élu à la Knesset, se pose dans sa poésie comme le défenseur de son peuple et de tous les opprimés. Convaincu que la vérité vaincra et que sur sa terre ne resteront ni usurpateur ni conquérant, il inscrit sa poésie dans une idéologie parfaitement militante. Mais sa lutte s'effectue à travers l'écriture et le verbe, il dit dans son poème Malyûna shamsin fî-damî (Mille soleils dans mes veines) :

"On m'a volé l'eau, l'huile, / le sel de mon pain, / ...On a volé ma bien-aimée, / ... On m'a tout volé sauf / le cour, / la conscience / et la langue ».

6 Cette attitude qui se veut pacifiste est confirmée dans son poème, intitulé Al-Ladhî amluk (Ce que je possède) où on lit :

"Je suis un homme simple, / je n'ai jamais porté ni canon ni fusil, / je ne possède que la musique, / et une plume pour exprimer mes rêves $\|^{2}$.

7 Sâlim Jubrân (1941), adhère au parti communiste en 1962 et devient rédacteur à la revue al-Ittihâd, et rédacteur en chef de la revue al-ghadd (Le Lendemain) publiée également par le même parti. Dans sa poésie militante et engagée, S. Jubrân associe savamment l'espoir et le désespoir, la joie et la tristesse. L'éloignement forcé de sa région d'origine, la Haute Galilée, n'affaiblit pas son attachement à cette terre. Il y est toujours et par la pensée et par le cœur. Sa terre est et restera belle. Il dit dans son poème Mâ yashâ' (Ce qu'il voudra) :

«La Galilée était eau et terre verdoyante / quand elle m'était interdite, / elle est devenue paradis / ses habitants devenus dieux / et ses nuits une lumière. /Je dis aux petits Césars: que vous êtes faibles! Vous m'empêchez de m'y rendre / mais mon cour voyage dans toute ma patrie / il y visite toutes les régions $\|^{3}$.

8 L'Arabe d'Israël, vivant une situation particulière, exprime une double allégeance : à l'État et ses lois d'une part, à son peuple et ses dirigeants d'autre part ${ }^{4}$. Il ressent des sensations contradictoires et opposées et souffre d'un écartèlement entre deux extrêmes. Sa poésie est souvent le reflet de ce déchirement. Dans le poème ash-Shabah (Fantôme), S. Jubrân, exprime la dualité de ses sensations, la coexistence de la joie et de la tristesse dans son cœur :

"Je sens la tristesse et la joie / ... Je sens que la vie est une nuit obscure / Et qu'elle est en même temps plus belle qu'un arc-en-ciel. / Entre une promesse qui reste sans suite, et une promesse pour l'avenir/ Je sens que mon cœur est à la fois / dans la solitude des tombes ... Et dans la fraîcheur des fleurs $»^{5}$.

9 Shafîq Habîb (1941), est emprisonné par les autorités israéliennes en 1990 à la suite de la publication de son recueil intitulé Awda ilâ l-mustaqbal (Retour vers l'avenir) où il est accusé d'avoir incité à l'intifada. Dans sa poésie, de facture classique, il crie sa colère contre l'occupant qui fonde son existence sur la violence. Un édifice fondé sur le sang, dit-il, sera sûrement ravagé et détruit. Et sur le même ton défiant et contestataire, il évoque Jérusalem, la ville sainte, où il exprime son désespoir de la voir gardée par des loups. ${ }^{6}$

10 L'engagement est explicitement exprimé dans cette poésie dite de la résistance. L'idéologie et l'objectif politique rendent le style simple et le texte accessible au grand public. Ceci étant, la poétique, chez ces poètes, est quelque part sacrifiée au profit du politique. 


\section{Émergence d'une nouvelle sensibilité poétique}

11 La poésie arabe en Israël connaît l'émergence d'une nouvelle sensibilité poétique. Face à la même crise politique, «la littérature et particulièrement la poésie s'avère capable d'approcher la violence sans pour autant être violente. Sans toutefois renoncer au rôle $\mathrm{du}$ poète et à son engagement culturel, social et politique $»^{7}$. La recherche d'une nouvelle esthétique fondée sur l'individualité et l'expérience personnelle forgée à travers la vie quotidienne s'opère à l'intérieur de cette poésie.

12 Michel Haddâd (1916-1997), prix du président de l'État d'Israël pour la littérature arabe en 1983, joue un rôle de premier rang dans le champ littéraire arabe en Israël. Fondateur en 1955 du premier "Comité des poètes arabes en Israël», il publie la revue al-Mujtama' (La Société) en 1954, et sera élu premier président du «Comité des écrivains palestiniens en Israël » en 1987. Poète prolixe, Michel Haddâd, aborde différents domaines dans sa poésie. Caractérisés par leur facilité relative et nourris de souvenirs, de nostalgie et de tradition populaire, les poèmes de Haddâd chantent la terre et loue la période de l'enfance. Bien que la politique et le militantisme ne constituent pas le moteur de sa poésie, il exprime dans plusieurs poèmes sa lassitude, son désespoir, mais aussi sa résolution à persévérer dans sa lutte à travers l'écriture. Il dit dans son poème Sawt (Voix) :

"Épuisé / À bout de souffles / Je n'ai plus de force pour lutter/ Mais je garde toujours ma

voix / Je crie au tyran pour s'arrêter ".

13 Antûn Shammâs (1950), a écrit trois recueils de poésie. Influencé par le symbolisme, il exprime la complexité de l'existence nationale, culturelle et linguistique des Palestiniens en Israël après $1948^{9}$. Soucieux de conserver la mémoire et les traditions de sa région d'origine, la Haute Galilée, il s'attelle à l'écriture pour les garder vivantes. Dans son poème intitulé Thumma kayfa sata'tî al-qasîda (Puis, comment arrivera le poème ?), il dit :

"J'ouvre la carte du monde, et je cherche un village que j'ai perdu, dans les poches de mon grand-père je cherche le reste des contes et les parfums. À son cou je m'accroche comme un papillon et je me balance..."

14 En tant qu'écrivain, il se considère investi d'une mission, c'est pourquoi il exprime sa crainte de la mort, qui peut l'atteindre avant qu'elle ne soit accomplie. Nous lisons dans le même poème :

"J'ai peur qu'un jour / les mots m'échappent/ tombent dans la rue / les enfants les attrapent pour en faire des queues à leur cerf volants / J'ai peur de mourir avant de tout dire. / À ce moment-là, personne ne se souviendra de moi $»^{10}$.

\section{Une nouvelle voix intimiste : une voix féminine}

Dans la poésie de Nidâa Khûrî ${ }^{11}$, nous découvrons une nouvelle voix poétique, une nouvelle approche de la résistance, du militantisme et de l'engagement. À l'intérieur de cette voie, ses œuvres marquent une évolution vers le personnel et l'intime.

L'écriture audacieuse et réflexive de $\mathrm{N}$. Khûrî déroge à une rhétorique habituelle qui a marqué pendant des décennies l'écriture arabe en Israël. Bien que le lexique et les thèmes qui animent son premier recueil U'linu laka 'an samti (Je te déclare mon silence) (1987) rappellent, dans une certaine mesure, ceux de la littérature palestinienne classique, l'ambiguïté des images et l'approche originale de la langue révèlent la 
profondeur d'un déchirement personnel et la finesse d'un engagement subtilement exprimé. Sa vision du monde extérieur s'articule autour du «Je » du poète, autour de cette écriture de soi qui devient le miroir reflétant l'extérieur avec tout ce qu'il représente comme amour ou violence.

Dans deux courts poèmes inaugurant le recueil, Nidaa Khûrî exprime une forte dichotomie qui marque toute son existence. Dans le poème intitulé Nidâ' (Appel) et qui est en même temps le prénom de l'auteur, elle se compare à une poule égorgée tiraillée entre « une souffrance » qui la mutile, la détruit et la neutralise et un « appel » nidầ. Un appel dont la source est «Toi ». Ce pronom anta (Toi) se réfère à un personnage masculin, indéfini, mais qui a une connotation positive dans le texte. Entre ces deux pôles, elle exprime son désarroi.

«La souffrance me mutile, ton appel m'attire, je frissonne, mes ailes se vautrent dans le

sang, je tombe ; je suis perdue $»^{12}$.

18 Le fusil et l'homme révolutionnaire, seule garantie de sa sécurité et seul espoir meublent le vide de sa vie.

19 Dans le troisième poème "Mot de passe ", elle établit une équation entre martyre et naissance et fait appel au "cavalier de la mort» pour lui apporter une patrie, une maison, une vigne. Elle fait appel à lui pour lui offrir toutes les conditions nécessaires à une nouvelle naissance. Le "mot de passe " pour accéder à cet espace réside dans le martyre, elle dit :

"Pour toutes les portes fermées il y a un mot de passe, / mon martyre serait dans toutes les rues du monde, mon anniversaire» (p. 24)

Les autres poèmes de ce recueil sont de la même veine. En effet, la quête de la joie de la poétesse passe par le sacrifice, le sang et l'attente. Le poème "Voiles levés pour le départ » illustre parfaitement cette quête : "Je construis dans mes forêts des nids de joie, et j'attends leur arrivée ", mais cette quête, associée dans le poème aux fêtes et aux noces, passe inéluctablement par son corps, car " au-dessus de mon corps », ditelle, « je construis des pistes pour la danse ». Ce sont « les cavaliers du sang rouge » qui ouvrent la fête. Un lien étroit s'installe entre le corps de la poétesse et ces acteurs, et le poème s'achève sur la consécration de cette union. Une intertextualité liturgique fait de cette union un sacrement. En effet, N. Khoury emprunte à la liturgie de l'Église grecque orthodoxe la formule énoncée par le prêtre consacrant le mariage des deux époux en mettant une couronne sur leurs têtes. Priant Dieu, le curé chante :

"Par les couronnes de la gloire et de la dignité, bénissez leur union ${ }^{13}$.

21 Ceci étant, une rédemption largement inspirée de la religion chrétienne constitue l'essence de presque tous les poèmes du second recueil Jiddilat ar-ra'd (Tresse de tonnerre) $(1989)^{14}$.

22 La poétesse, avec une nette focalisation sur son "Moi", sur son corps et sur ses sensations, s'adresse dans ses poèmes à un interlocuteur masculin qui reste toutefois sans identité précise. Cet interlocuteur désigné par la deuxième personne du singulier semble avoir plusieurs référents dans les textes. Il désigne parfois « la patrie » al-watan, masculin en arabe, et parfois « la terre » à laquelle elle appartient. Toutefois, les limites de la patrie sont aussi confuses. Est-ce la patrie dans laquelle elle vit ou bien est-ce la patrie perdue ? Cette ambiguïté volontaire reflète parfaitement l'image d'une poétesse déchirée et tiraillée par des sensations contradictoires. 
Ceci étant, le « Toi » dans le poème «Tresse de tonnerre », toujours non identifié, se réfère probablement à l'Israélien. Dans cette confrontation entre le «tu » et le «je ", Nidâ' Khûrî dénonce, avec la subtilité habituelle de sa poésie, un cycle de violence sans issue. Elle reproche à l'Israélien - qui connaît plus que tout autre le sens de la mort et de la peur - de transmettre à son tour la peur à la poétesse, à ce « Moi / Je » qu'il feint d'ignorer et dont il ne reconnaît pas la présence. Malheureusement, cette union dans la peur ne fait qu'engendrer "le fusil ", "la mort " et les "fous de la révolution » et «toute la peur de l'histoire » dit-elle. La poétesse aspire profondément à une union, mais sans armes ni violence. Quand elle était petite, on lui a raconté l'histoire des «fours » et elle a beaucoup pleuré. Elle a même détesté le pain parce qu'il est associé dans son esprit et dans son imaginaire au four. Juste à la fin de ce passage, elle définit son destinataire. Le « Tu » est remplacé par « l'Homme », «l'Être humain », et à cet être humain elle exprime son amour et sa passion. Elle le serre dans ses bras pour annoncer la liberté et la vie symbolisée par les " palmiers » ${ }^{15}$.

Dans le poème "L'endroit où je ne suis pas ", la poétesse se replie sur elle-même dans une ultime tentative de trouver son identité. Mais, à l'instar du recueil précédent, elle souffre d'une déchirure douloureuse :

"Quand je reviens à moi-même / je me débarrasse de tout ce qui est en moi / je m'approche de mes lèvres / je pose sur ma bouche des baisers silencieux / quand, à la tombée de la nuit, je rentre dans ma peau / je me sens seule / J'apprécie la liberté / j'embrasse l'amour ".

Mais cette quiétude n'était qu'illusion. Car elle ajoute :

"Je me vois en deux moitiés / j'essaie de coller les deux morceaux / j'essaie de presser une moitié dans l'autre / j'essaie de boire / d'être une seule moitié/j'essaie, mais en vain, d'être «Moi-même» tout court »'.

Dans les recueils suivants, la poétesse s'éloigne de plus en plus du politique pour un clair retour à l'intime et au sentiment personnel. Cette tendance s'annonce dès le premier poème qui introduit le recueil Zunnâr ar-rîh (Ceinture de vent) ${ }^{17}$. En s'adressant à son partenaire désigné par le pronom personnel «tu», elle s'aventure dans l'irraisonnable, dans l'errance et dans le désir de libérer son parcours de tout itinéraire tracé au préalable et balisé par les codes de la société. Elle emprunte à cette fin la métaphore du "vent »: une "ceinture faite de vent », dit-elle, qui est susceptible de l'emporter vers un univers de folie où elle s'épanouit loin du joug de la raison :

"J'ai aimé les nuages, j'ai aimé le brouillard

Et il ne me reste qu'à aimer le vent

Autour de ma taille, je noue une ceinture faite de vent et je m'envole vers la folie ${ }^{18}$."

Ce recueil est en effet un hymne à la femme. Une femme qui se construit en dépit de la volonté de l'homme.

7 Divisé en six parties, le premier poème «Liturgies orientales » consacre la première partie à la femme et à son statut en Orient. Celle-ci est considérée par l'homme comme un objet à consommer. Son rapport à elle est comparable au rapport qu'il a avec son " Narguilé ». Nidâa Khûrî exprime sa révolte dans les chapitres suivants: «Fils des ténèbres qui t'a donné un pouvoir sur moi $»^{19}$, dit-elle à l'homme oriental.

Le dernier poème du recueil, « Mémoire du blé » reprend certaines images évoquées dans le premier poème, et consacre la femme comme source de vie. Dans un tableau empruntant aux traditions villageoises l'ensemble de ses éléments, la femme est associée au blé décrit comme symbole de la vie. Le rapprochement dans le dernier 
poème entre la femme qui broie le blé et la femme qui met les enfants au monde confirme ce symbolisme. On lit dans le premier poème :

"Oh toi femme de blé, de fumée et de bois.

Dans ton giron, tu grènes le blé, tu brûles le bois et la fumée s'élève... »

Alors que le dernier poème s'achève sur ce passage clôturant le recueil :

"Avec la paille, sur les aires de battage, elle [la femme] tresse des plateaux / Dans son giron, elle tamise les nuages / Le blé tombe / Elle le broie / Entre ses jambes, la meulière tourne / Le blé concassé tombe / Il mûrit / Elle enfante / La meulière eut le vertige / Nous sommes comblés $»^{20}$.

Force est donc de constater que, dans sa quête initiatique, la poétesse crée son univers poétique en puisant l'essentiel de ses éléments à deux sources principales: la vie quotidienne et tout ce qui constitue la mémoire de la vie paysanne; le domaine religieux et notamment la religion chrétienne. Plusieurs titres de ce dernier recueil sont d'ailleurs empruntés à la Bible, Ancien et Nouveau testament: «Liturgie de la Pâque ", "Évangile de la colère ", Asfâr al-kufr (Chapitres de l'impiété); Ishâh al-lahab (chapitres des flammes). Elle se réfère, dans ce même recueil à la Cène, le dernier repas $\mathrm{du}$ Christ avec ses disciples la veille de sa crucifixion. Et comme le Christ, elle dit « Je prends le pain, le romps en deux morceaux : l'un en signe de foi / Et l'autre en signe de faim et j'attends / Ma première communion.. ${ }^{21}$.

\section{Conclusion}

La poésie arabe en Israël présente des caractéristiques communes qui sont dues au contexte sociopolitique dans lequel vivent poètes et citoyens arabes. L'une des caractéristiques qui marquent profondément cette poésie et la littérature arabe en général est la dualité, ressentie et exprimée par l'écrivain. Le tiraillement entre deux appartenances et la quête identitaire constituent l'un des axes principaux qui unissent les poètes. Mais cette poésie, surtout la contemporaine, loin d'être une illustration uniforme, est riche d'une large diversité sur les deux plans : thématique et expression poétique. Elle s'impose pleinement dans le champ littéraire israélien et arabe et prend part, à travers ses expérimentations, à la mouvance novatrice postmoderniste.

\section{BIBLIOGRAPHIE}

AS-SAFADI, Mutâ' (1973), Introduction aux CEuvres Complètes de Samîh al-Qâsim, Dâr al-Awda, Beyrouth.

BALLAS, Shimon (1980), La Littérature arabe et le conflit au Proche-Orient, Anthropos, Paris.

DESCAMPS-WASSIF, Sara (1999), Dictionnaire des écrivains palestiniens, Institut du Monde Arabe.

EYBEN, Shemon (1992), Jisr bayna thaqâfatayn (Un pont entre deux cultures : poèmes choisis, arabes et hollandais), Mu'assasat al-hijra, Amsterdam. 
HABIB, Shafîq (2001), Sârikh fî-l-barriyya (Un cri dans le désert), al-Hakam li-t-tibâ‘a wa-n-nashr, Nazareth.

HADDÂD, Michel (1984), Min arsifat al-hurriyya (Troittoirs de la liberté), Dar al-mashriq, Shafa Amr.

JUBRAN, Sâlim (1972), « Qasâ'id laysat muhaddadat al-iqâma » (Poèmes sans résidence fixe), Nazareth, in Salma al-Khadrâ' al-Jayûsî.

KHÛRÎ, Nidâa (1987), U’linu lakum ‘an samtî, Acre.

KHÛRÎ, Nidâa (1992), Zunnâr ar-rîh, Matba'at Abû Rahmûn, Acre.

ZAYYAD, Tûfîq (1966), « Ashuddu alâ ayâdîkum » (Je serre vos mains), in Salma al-Khadrâ' al-Jayûsî, Mawsû'at al-adab al-filastîni al-mu'âsir (Anthologie de la poésie palestinienne moderne, vol. 1, La Poésie), al-Mu'assasa al-arabiyya li-d-dirâsât wa-n-nashr, Beyrouth.

\section{NOTES}

1. Voir : al-Qâsim (1973), p. 23.

2. Voir : Zayyâd (1966, dans éd. 1997), p. 265.

3. Voir : Jubrân (1972), p. 172.

4. Voir : Ballas (1980), p. 55.

5. Ibid, p. 172.

6. Voir : Habîb (2001), p. 7.

7. Voir : Eyben (1992), p. 270.

8. Voir : Haddâd (1984), p. 45.

9. Voir : Descamps-Wassif (1999), p. 101.

10. S. al-KH. Al-Jayûsî, op. cit., p. 298.

11. Nidâa Khûrî est née à Fassûta en Galilée en 1959, le même village où est né Antûn Shammâs, elle obtient son baccalauréat à l'école des sœurs de Saint-Joseph à Nazareth. Diplômée de philosophie et de littérature comparée de l'université d'Haïf, elle est membre de l'Union des écrivains arabes. Son recueil an-Nahr al-hâfî (Fleuve nu), fut traduit en hébreu en 1990, Édition Sefarim.

12. Voir : Khûrî (1987), p. 20.

13. Ibid., p. 72

14. Dâr al-Mashriq, Shafâ 'Amr, 1989.

15. Ibid., p. 86.

16. Ibid., p. 60.

17. Voir : Khûrî (1992).

18. Ibid., p. 7.

19. Ibid., p. 21.

20. Ibid., p. 138.

21. Ibid., p. 24. 


\section{RÉSUMÉS}

La cause palestinienne chez les poètes arabes israéliens.

Le présent article s'évertue à montrer les mouvements marquant l'évolution de la poésie arabe en Israël, dans un contexte contradictoire. Il souligne trois tendances principales. La première, explicitement militante, développée dans le giron de la Rakah, parti communiste israélien. Destinée à un public particulier et animée par une idéologie de combat, elle sacrifie parfois la poétique au profit de la politique. La deuxième tendance semble d'une nouvelle esthétique poétique basée sur l'individualité et l'expérience personnelle. La troisième voix poétique, profondément intimiste, est représentée par la poétesse Nida Khoury. Son approche de la résistance et du militantisme, ainsi que son approche originale de la langue révèle la profondeur d'une déchirure personnelle et la finesse d'un engagement subtilement exprimé.

Enfin, le tiraillement intérieur entre deux appartenances et la recherche identitaire constituent l'un des principaux thèmes qui unissent les poètes de ces trois tendances.

The present article focuses on showing the movements marking the evolution of Arabic poetry in Israel in a conflicting context. It points out three main tendencies. The first one, explicitly militant, developed in the lap of the Israeli communist party Rakah. Intended for a general public and animated by an ideology of fight, it sometimes sacrifices the poetics for the benefit of politics. The second tendency looks for a new poetic aesthetics based on individuality and personal experience. The third poetic voice, profoundly intimist, is represented by the poet Nidâ 'Khoury. Its approach of the resistance and the militancy as well as its original approach of the language reveal the depth of a personal tearing and the finesse of a subtly expressed commitment.

Finally, the interior tugging between two belongings and the identical seeking constitute one of the main themes which unite the poets of these three tendencies.

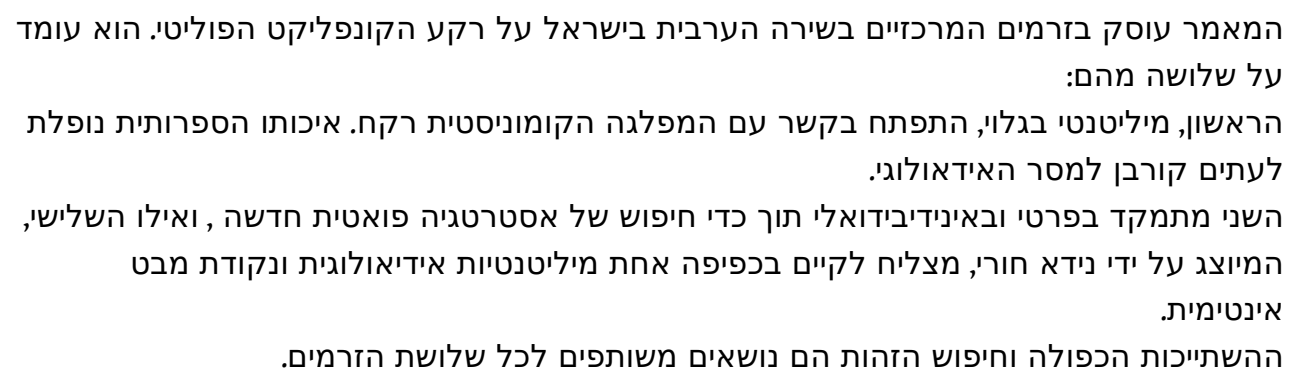


INDEX

Mots-clés : littérature arabe, arabes et Israéliens, militantisme, intimisme, individualité,

féminisme, Kanafânî Ghassan (1936-1972), Zayyâd Tûfîqc (1929-1994), Jubrân Sâlim (1941), Habîb Shafîq (1941-), Haddâd Michel (1916-1997), Shammâs Antûn (1950), Khûrî Nidâa (1959-), quête identitaire

Index chronologique : vingtième siècle

Index géographique : Israël, Palestine

Keywords : Arabic literature, Israel, Palestine, Arabs and Israelis, militancy, intimism, feminism, Kanafânî Ghassan (1936-1972), Zayyâd Tûfîqc (1929-1994), Jubrân Sâlim (1941), Habîb Shafîq

(1941-), Haddâd Michel (1916-1997), Shammâs Antûn (1950-), Khûrî Nidâa (1959-), quest for identity, literature, twentieth century

Thèmes : littérature

\section{מילות מפתח}

ערבית ספרות, ישראל, פלסטין, ערבים וישראלים, המיליטנטיות, פרטיות, פמיניזם, ע: 'סאן כנפאני, סלים ג'ובראן, שפיק חביב, מישל חדד, נדאא ח'ורי, המאה העשרים, ספרות 